\title{
Study on Nixing Pottery Brand Image Promotion Tactic Strategy Under the Context of Guangxi Regional Economy
}

\author{
Xingguo $\mathrm{Xu}$ \\ Guangxi Technological College of Machinery and Electricity, Nanning, 530007, China
}

Keywords: Regional economy, Nixing pottery, Brand image, Promotion strategy

\begin{abstract}
The present situation Nixing-pottery market analysis, starting from the principle to follow brands, proposed Nixing pottery industry to build a culture of high artistic quality, visibility and influence of large, competitive market, cultural industry a pillar of sustainable development and other promotional strategies. In this paper, Qinzhou Nixing pottery cultural industries as a carrier, Regional Economic Research Guangxi Nixing pottery brand promotion strategy.
\end{abstract}

\section{Introduction}

Qinzhou Nixing-pottery has a thousand years of history, is one of "China's four famous pottery", Chinese arts and crafts is a wonderful work in the garden, but also a cultural ambassador outreach Qinzhou and Qinzhou city card. Nixing pottery species diversity, mainly tea, tea sets, utensils, coffee, flower pots, a plurality of smoked tripod, antique technology products and traditional crafts products, such as 1000 (Figure 1). Its magical "kiln" art unique in the domestic ceramic industry, Qinzhou Nixing pottery after years of heritage and innovation development, brand influence and increasing visibility. October 2009, Nixing-pottery named the Sixth China - ASEAN Expo State ceremony in 2010, Nixing-pottery selected for the Shanghai World Expo licensed products, in June 2008, was approved by the State Council as a national intangible cultural heritage. In January 2013, awarded the Qinzhou City, "China Nixing pottery" title China Arts and Crafts Association.

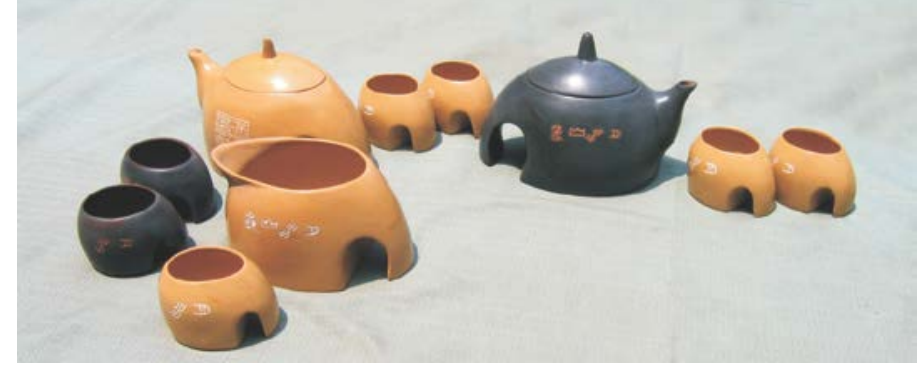

Fig. 1. Shuai Ligong Xiangshan Moonwater teapots

\section{Analysis of Nixing-pottery market status}

Currently Nixing-pottery industry development and marketing breakthrough in the market, but look at the overall development, still has the following advantages and disadvantages.

Competitive Advantage:

1). Broad market demand

Today, the tea market, decorations market, gift market is the fast, strong consumer market demand, has great potential. Therefore, Nixing-pottery tea as green and healthy products, exquisite home and 
office accessories, high cost of locating cultural gifts, will certainly win a huge consumer market space.

2). Advantages of Nixing pottery products

Nixing-pottery clay rich in iron, zinc, calcium and minerals beneficial to human body, free from influence of the glaze, is truly "green ceramic", "health Tao." Green is the mainstream of today's consumer, health-oriented life today, green products to consumers must be sought after.

Competitive disadvantage:

1). The need to further expand the brand influence

Nixing-pottery production enterprises in the business, scale and technology with other name Tao exists obvious disadvantage compared, and low in the domestic ceramics market's influence and visibility. Daily Tao failed to break into the domestic and foreign markets, household pottery market share is low, no obvious competitive advantage [1]. Therefore, by means of long-term accumulation of non-heritage brand awareness, awareness of the region evoke nostalgic consumers, enhance their sense of pride and belonging, and expand non-heritage brand awareness across regional space limitations, increase awareness groups outside the region, compared with a national reputation high brand.

2). The grave shortage of innovation ability

Nineties of last century the loss of business caused by the fall Nixing-pottery talent and technology, talent shortage, currently in production, most of the design line are advanced in age, some traditional handmade scarce talent.

In 2012, Nixing-pottery production enterprises with a total of more than 200, through which 105 enterprises have registered other unregistered small farm house or a small workshop in the Nixing-pottery industry practitioners about 1.2 million people, Nixing Tao practitioners to skilled workers as the main body. Until August 2015, the national industrial and commercial registration Nixing-pottery production and operation of manufacturers and there are 145 workshops, employing about 8,000 people in the whole industry total production value of about $\$ 500$ million. However, fewer high-level technical personnel, national arts and crafts masters called David, only two, the number of arts and crafts masters team has only 62, even professional designers are only 200 people. Meanwhile Nixing-pottery heritage and development of production technology there are many flaws. Thus, Nixing-pottery industry, the talent shortage is a serious problem.

3). Expand the sales market

Marketing is the main channel for promotion, but now Nixing pottery sales backward, single way, showed a small amount of orders for sales, although some companies have begun to use the Internet for sales, but due to the small size of the business, the brand is not strong, little influence on the market, the poor sales performance. The market development at home and abroad is less, insufficient market development efforts.

4). The development of the brand faces constraints

First play Qinzhou resources, integration of quality resources are subject to further intensify. Nixing pottery Although prominent historical and cultural characteristics, welcomed by consumers flagship Bestsellers still insufficient. Second, brand management and institutional mechanisms for the development of the current demand is still incompatible, need to vigorously explore and improve. Third, the brand promotion efforts is still insufficient, the need for the domestic and overseas markets to further enhance the brand influence.

\section{Principles Nixing-pottery branding to be followed}

Nixing-pottery products in Guangxi have strong national characteristics and advantages of the integration of multi-ethnic culture. Therefore, create brand Nixing-pottery, essential in the development of the need to seek their own characteristics, and after a long period of precipitation and accumulation.

\section{Cultural principle}


China's economic, cultural and becoming more and more international, Nixing-pottery market in brand building process, the need for cultural development as the main channel for Nixing-pottery gives a broader meaning, so that enterprises can Nixing-pottery culture go further down, he argued, the development of better. Nixing pottery itself has a very unique elements of national culture, is unmatched by other ceramic combines hydrangea, long drum and brocade and other high national cultural connotation of the visual elements in Nixing pottery products, Nixing-pottery branding added these cultural elements can effectively stimulate consumer thinking and emotional resonance, so Nixing pottery brand to popular. For example, China's more famous Nixing-pottery works "high drum Vase", on the shape draws Guangxi region long drum and Timbal image and charm of ancient use, and integrated into the Zhuang Zhuang Jin, Fresco and other elements, through the integration of elements of national characteristics and use, Guangxi Ethnic culture profound show in the world [3]. (Picture. 2)

In addition, Guilin, Guangxi region Xiangshan, Shuiyuedongtian Lingshan lychee and national characteristics of the landscape is Nixing pottery Zhongliang good decorative themes, through the application of these elements to highlight the Nixing pottery cultural connotation and innovative style of the times.

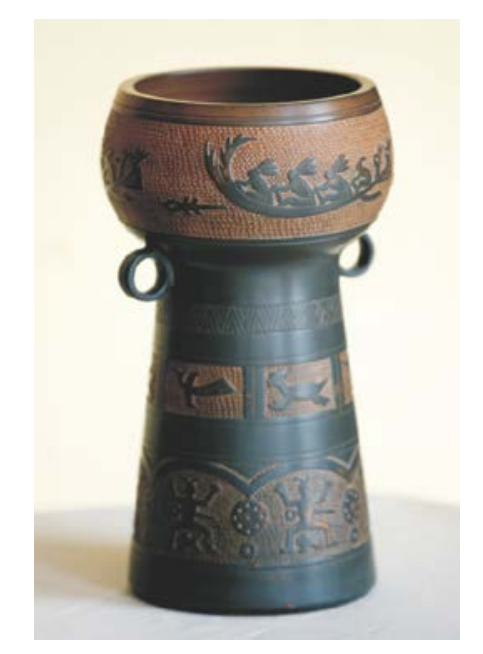

Fig. 2. Li Renping Wine goblet

\section{Peculiarity principle}

Unique is the biggest advantage of competition in the market, it is a major factor in brand promotion. In shaping Guangxi Nixing pottery brand image, it needs from Nixing pottery uniqueness start looking Nixing pottery is unique, so Nixing pottery brand more unique and can not be copied. Nixing pottery Tao is the only one of the four names in minority areas of ceramic products, has a unique national characteristics, but also in the firing process does not need to be Pi-glazing pottery, but through the efforts of different colorful polished to render colors, which is consistent with contemporary environmental awareness. More respected modern green concept of environmental protection, in the purchase of goods tend to be more original ecosystem, it will make eco-friendly materials or the original product as the first choice, Nixing-pottery can use this idea to win the favor of consumers, thereby open the domestic and foreign markets.

\section{Long term principle}

Branding is not achieved overnight, and requires a long stick, Nixing-pottery in the development of the need for targeted promotion of culture, so as to create a good cultural influence, so Nixing pottery people can be recognized and accepted. The current rise of the Nixing pottery in just ten years, a brand is just started, branding and development still takes a long time to accumulate and precipitation, and continue to improve the brand, with the characteristics and the unique fusion of cultures show to make the brand bigger and stronger.

\section{Nixing pottery brand image promotion strategy}




\section{Rely on location advantages, build cultural exchange platform}

Beibu Gulf Economic Zone in Guangxi coastal border, along the river, located in southern China economic circle, combined with Southwest and ASEAN economic circle economic circle, is the only, but also China and ASEAN and ASEAN two-way open land bordering both provinces have sea lanes , an important bridge and gateway to two-way communication, the advantage is significant. Since the early 1990s, China - ASEAN Free Trade Area, make Guangxi Beibu Gulf Economic Zone as a platform for China and ASEAN exchanges and cooperation. Promote regional economic cooperation and the Opening. Qinzhou Guangxi Zhuang Autonomous Region is located in the southern coast, is centrally located in Guangxi Beibu Gulf Economic Zone in Guangxi 'South (Ning) North (Sea) Chin (state) anti (Harbor City) "urban agglomeration centers and South China Economic Circle and ASEAN economic circle junction (Fig. 3), since ancient times is the "China Marine Silk Road" leading to an important port in Southeast Asia, South Asia. In the economic globalization and regional economic integration background, Qinzhou become China - ASEAN most convenient international channel, an important platform for economic and trade exchanges and cultural exchanges.

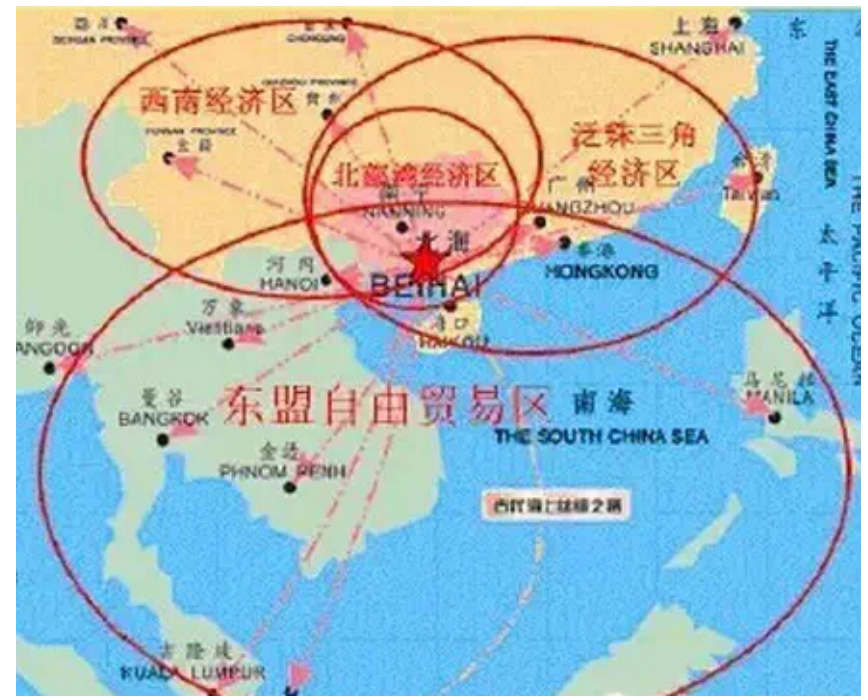

Fig. 3. Guangxi Beibu Gulf Economic Zone

\section{Build brand image, promote brand strategy}

Refining ethnic culture, accelerate research and innovation performance.

Qinzhou Nixing pottery long history, rich cultural resources, promote regional characteristics of cultural and creative industries in Guangxi brand, Nixing-pottery accelerate product innovation. Nixing pottery utilizing the unique natural environment heavy human environment to create regional cultural brand. Qinzhou culture is characterized by brawny populated areas, there are distinctive folk culture: There are picking, playing flower floor, sea songs, dragon dance, jump Lingtou, sing Chunniu etc. (Figure 4). It is the culmination of history, culture, landscape, folk culture and modern culture. Therefore, Nixing-pottery product innovation and technology to enhance the focus on aspects of this feature to speed up research and innovation performance. 


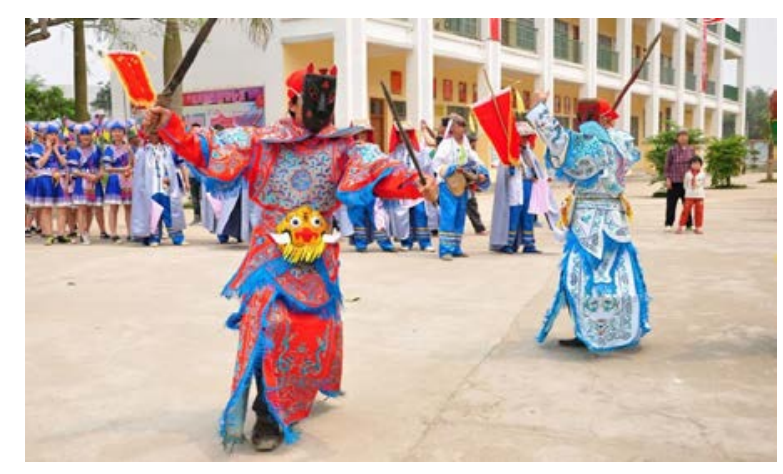

Fig. 4. Tiaolingtou Qinzhou folk culture

Build 020 model, to achieve the integration of online and offline marketing.

From small to daily necessities, large home appliances; spike, penny auction, REWARDS, etc., all the concept of online shopping, online marketing has become an important area to expand the market share of traditional retailers. Traditional retailers to online retail enterprises can extend the size according to choose between two different paths: Nixing pottery large enterprises choose traditional retail and online retail operating independently, SMEs can become the main traditional retail, online retail, supplemented by the way. The key to achieve multi-channel retailer online and offline co-operation between the two is that the co-channel marketing strategy, which is to fully tap the potential of online and offline two markets, to achieve the overall interests of the enterprise to maximize play a positive role in the promotion. In the future, the online and offline marketing model will become the co-operation of China's famous ceramics Nixing-pottery business tool, to create more value for the enterprise and customers.

To foster the cultural industry brand, increase promotional efforts.

First, create art and culture brand. Promoting Qinzhou characteristics of advanced culture, promoting the "China Qinzhou Nixing pottery" brand development focus at the same time, the "mountain", "sea" as the theme, the Qinzhou gorgeous landscapes and stunning ocean scenery and a long history and culture, rich folk culture combine well, into the modern design concepts to create art and culture has a rich cultural heritage of the brand.

Second, in the efforts to foster regional characteristics of cultural and creative industries in Guangxi brand, based on the use of powerful enterprises subject to brand development, greater use of large-scale cultural industry groups to do bigger and stronger Nixing pottery culture and creative industries brand. Current Qinzhou municipal government to actively promote Qinzhou Nixing pottery cultural and creative industrial park construction, the future will Nixing-pottery culture and creative industry park as a link, forming cultural roots concept, efforts to build Nixing-pottery culture features and antiques, paintings, flowers, birds, Genyi , rocks, fine culture, shopping and cultural tourism and leisure enclave, thereby creating new business card Qinzhou characteristics of cultural tourism. The park planning area of about 2700 acres, a total investment of about 1.56 billion yuan. 1669.78 acres of land for a project. Project planning for the future 3--5 years to achieve Nixing pottery and extend the industrial output value of one billion yuan, 1.5 million people in employment in the industry. (Picture. 5) 


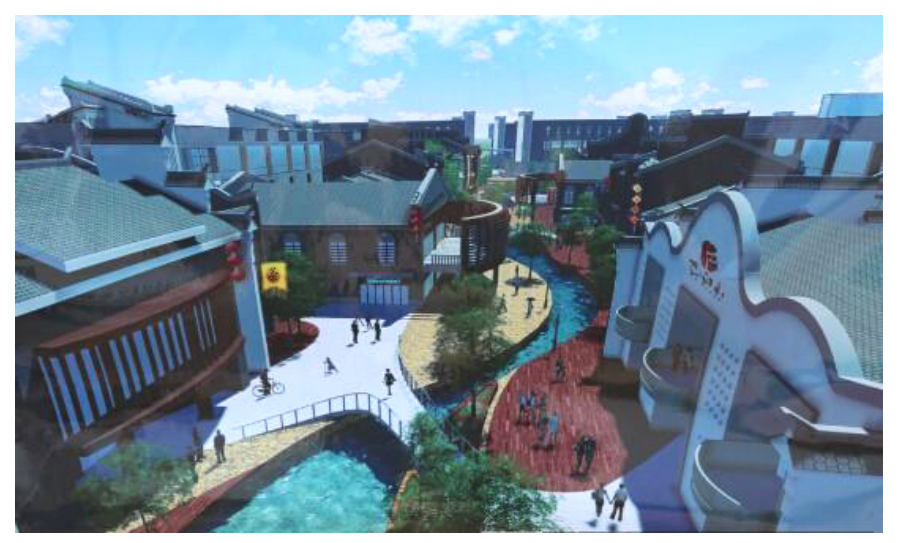

Fig. 5. Qinzhou Nixing pottery Cultural and Creative Industry Park

The third is to build Qinzhou Nixing pottery tourism products and promote non-left art heritage. Qinzhou cultural tourism has potential advantages, set sea, beach, forest, stone as one of the large outer ring and sand Sanniangwan; six Mountain, mangroves, fruit mountain, fog Hill and Forest Park, the formation of "Aboriginal" tourism resources. There are national heroes of modern history, "Liu FENG first", "first village in Guangxi couplets," the big reed ancient buildings and other human landscape. Qinzhou tourism product development provides a wealth of creative material, is a national culture heritage deep understanding and accurate grasp of local characteristics, innovation needs to understand the spiritual needs of the modern traveler, be distinctive creative, cultural connotation of products with unique form and the times demand characteristics manifested, will be turned into rich tourism resources inherent in the scientific and cultural connotation of tourism products outside the charm, so Nixing pottery tourism products rich cultural tastes, thereby increasing the added value of culture, tourism resources so deeply modern traveler and the lives of consumers. At the same time, through the promotion of one of China's four famous pottery of Qinzhou "Nixing-culture", mining historical and cultural context and coastal Lingnan culture, cultural tourism brand to build Qinzhou, Qinzhou stimulate the development of cultural tourism, so as to further promote the art of non-genetic inheritance .

Fourth Nixing pottery brand image promotion do the following: (1) establish Nixing-pottery culture and creative industry park propaganda billboards. (2) both sides of the main road Qinzhou Nixing-pottery culture erected billboards, making a unified album, videos and posters. (3) Qinzhou and national trade associations jointly organized the annual ceramics exhibition, organized provincial media strong publicity, to expand the industrial regional brand influence. (4) regularly organizes regional enterprises to participate in exhibitions and competitions at home and abroad to promote regional brand exhibition in Qinzhou, expand Nixing pottery visibility. (5) Organization of Chinese and foreign brands, quality and other experts on SMEs Nixing pottery were training to help establish a corporate culture. (6) by the Qinzhou Nixing pottery Industry Association, led a registered trademark Nixing-pottery industry, industrial regional brand intellectual property protection.

\section{Conclusion}

In summary, in the context of regional economic development in Guangxi, Nixing pottery must show their own advantages, combined with the characteristics of their cultures, thus highlighting the healthy, high-end, green brand, and using a variety of publicity Guangxi Nixing pottery to promote, increase its visibility and influence, making it a place in the domestic and international markets.

\section{Acknowledgments}


This article is 2013 Guangxi Zhuang Autonomous Region Department of Education Humanities and social sciences research funded projects, project name :( Guangxi) Nixing pottery brand image under the regional economic promotion of research background, number: (SK13YB152).

\section{References}

[1] Wu Xiaoling. On Inheritance and Industry Development of Nixing Pottery culture, Qinzhou College Journal, 2013,28 (6): 6-10.

[2] Zhang Shilun, Yan Yan. Inheritance and Industry Development of Nixing Pottery culture, Foshan ceramics, 2013, 23 (8): 38-42.

[3] Ma Peiyuan. Qinzhou Nixing pottery' s brand development at perspective of creative industry, Art Science and Technology, 2014 (5): 109-109,120.

[4] Zhou Sanping. Discussion on brand building of Guangxi Qinzhou Nixing pottery industry, Popular Literature, 2014 (22): 261.

[5] Xu Xingguo. Promotion strategy to build the brand Nixing pottery, Ceramic Science and Art, 2012,46 (12): 49-51.

[6] Qinzhou Municipal People's Government to speed up a number of opinions on Nixing pottery Industrial Development, Qin Zheng Fa [2007] No. 8. 